\title{
Genetic and Molecular Insights into the Enhancement of Rice Yield Potential
}

\author{
Jong-Seong Jeon • Ki-Hong Jung • Hyun-Bi Kim • \\ Jung-Pil Suh • Gurdev S. Khush
}

Received: 23 December 2010 /Revised: 30 December 2010 / Accepted: 2 January 2011 /Published online: 19 January 2011

(C) The Author(s) 2011. This article is published with open access at Springerlink.com

\begin{abstract}
Rice is one of the most important global food crops and a primary source of calories for more than half of the world's population. Rice production increased steadily during the green revolution era primarily as a result of introducing high-yielding rice varieties. World rice production increased at a rate of 2.3-2.5\% per year during 1970 s and $1980 \mathrm{~s}$, but this rate of growth was only $1.5 \%$ per year during the 1990s. The yield growth rate for rice has further declined during the first decade of this century. However, the populations in the major rice-consuming countries continue to grow at a rate of more than $1.5 \%$ per year. According to various estimates, world rice production must increase at the rate of 2 million tons per year. To meet this challenge, rice varieties with higher yield potential and greater yield stability are needed. Various strategies for increasing the yield potential of rice include; (1) conventional hybridization and selection, (2) $F_{1}$ hybrid breeding,
\end{abstract}

\author{
J.-S. Jeon • K.-H. Jung • H.-B. Kim • G. S. Khush $(\bowtie)$ \\ Crop Biotech Institute, Kyung Hee University, \\ Yongin 446-701, South Korea \\ e-mail: gurdev@khush.org \\ J.-S. Jeon $\cdot$ H.-B. Kim • G. S. Khush \\ Graduate School of Biotechnology, Kyung Hee University, \\ Yongin 446-701, South Korea \\ K.-H. Jung \\ Department of Plant Molecular Systems Biotechnology, \\ Kyung Hee University, \\ Yongin 446-701, South Korea \\ J.-P. Suh \\ National Institute of Crop Science, RDA, \\ Suwon 441-857, South Korea \\ G. S. Khush \\ Department of Plant Science, University of California, \\ Davis, CA 95616, USA
}

(3) modification of plant architecture, and (4) enhancement of photosynthesis. Many genes and QTLs have recently been identified which will assist with rice breeding objectives.

Keywords Breeding · Ideotype $\cdot$ Photosynthesis $\cdot$ Rice . Yield

\section{Introduction}

Rice (Oryza sativa L.) is the most important food source for more than half of the world's population. Major advances in increasing rice production have occurred during the last four decades through the adoption of green revolution technologies based primarily on the availability of high yield varieties. World rice production increased at the rate of $2.3-2.5 \%$ per year during $1970 \mathrm{~s}$ and $1980 \mathrm{~s}$. However, during the $1990 \mathrm{~s}$, this growth rate has reduced to $1.5 \%$ annually. This yield growth rate has further declined during the present decade (http://www.fao.org/docrep/005/ac484e/ ac484e08.htm). For example, the average rice yield in China increased from 5.4 to $6.4 \mathrm{t} / \mathrm{ha}$ between 1987 and 1997, but no clear increase was achieved between 1997 and 2007 (Peng et al. 2009). Significantly, the number of rice consumers is growing at the rate of $1.5 \%$ per year, whereas rice production is now only increasing at the rate of $1.0 \%$ per year. To make up this shortfall, rice stocks are being accessed, but global rice stocks have declined from 147 million tons in 2001 to 82 million tons in 2008 (Mohanty et al. 2010).

According to UN estimates, the world's population will increase from 6.7 billion at present to 8 billion in 2025 (http://www.un.org/esa/population/publications/longrange2/ WorldPop2300final.pdf). According to various estimates, 
world rice production must increase from 440 million tons at present to 475 million tons in 2020 (Mohanty et al. 2010). The FAO estimates that world rice requirements will be 524 million tons in 2050, requiring a yearly increase of 2 million tons from the present production levels. If this challenge of producing more rice from existing land resources is to be met, rice varieties with a higher yield potential will be required. In this review, we summarize the various genetic and molecular approaches that are currently being adopted to increase the yield potential of rice. These include (a) conventional hybridization and selection; (b) $\mathrm{F}_{1}$ hybrid breeding; (c) modification of the plant architecture; and (d) enhancement of photosynthesis.

\section{Conventional Hybridization and Selection}

Traditional cross hybridization and selection is still a widely used strategy for developing cultivars with a higher yield potential. In this methodology, the segregating populations derived from crosses between two parents are screened for desirable recombinants, and selected fixed lines are evaluated in replicate yield trials. This approach is therefore based on the variability created through hybridization between diverse parents and the subsequent selection of desirable individuals. Cross hybridization and selection has contributed on average to about a $1 \%$ increase per year in the yield potential of rice since the development of IR8, the first improved semidwarf (short statured) rice variety (Peng et al. 2000). However, hybrid sterility in rice can often hinder the transfer of useful genes during intersubspecific crosses. The molecular basis of this hybrid sterility is usually complex, often involving the cumulative effects of gene interactions at multiple loci (Ouyang et al. 2010).

In recent studies, two hybrid sterility genes, $S 5$ and $S a$, involved in the indica-japonica subspecies hybrid sterility, have been cloned (Chen et al. 2008; Long et al. 2008). The hybrid female sterility gene $S 5$ was found to encode an aspartic protease. Interestingly, among the three indica $(S 5-\mathrm{i})$, japonica $(S 5-\mathrm{j})$, and neutral $S 5(S 5-\mathrm{n})$ alleles in rice, $S 5$-n carrying variety produced fully fertile hybrids from a heterozygous genetic background with either of the incompatible alleles (Chen et al. 2008). The $S a$ locus, involved in conditioning hybrid sterility, was found to consist of two adjacent genes, SaM encoding a small ubiquitin-like modifier E3 ligase-like protein, and $\mathrm{SaF}$ encoding an F-box domain-containing protein (Long et al. 2008). This study also identified three $S a$ haplotypes (indica, japonica, and compatible), thus proposing a two gene/three component interaction model for hybrid sterility. Hence, the introgression of these wide-compatibility genes (WCGs; neutral or compatible alleles) may provide a means to break the sterility barrier between indica and japonica subspecies.

Crop gene pools have been increased through the hybridization of cultivated rice with wild rice species (Brar and Khush 1997). These pools have made it possible to improve a number of important traits including yield potential. As an example, some backcross derivatives from a cross between Oryza rufipogon from Malaysia and cultivated rice resulted in a strain with an $18 \%$ greater yield than the recurrent parent. The increased yield potential of these interspecific derivatives has been attributed to higher vegetative growth rates or early seedling vigor (Xiao et al. 1996). Hybrid incompatibility in the $F_{1}$ generation between specific cultivars and their wild relatives is often a major reproductive isolation barrier. Recently, the reciprocal loss of duplicate genes encoding mitochondrial ribosomal protein L27 at two loci, $S 27$ and $S 28$, was found to cause pollen sterility in hybrids of $O$. sativa and its wild relative Oryza glumaepatula (Yamagata et al. 2010). Furthermore, this demonstrated that the introduction of a functional allele, essential for the later stage of pollen development, could overcome hybrid sterility between cultivated rice and wild relatives.

\section{$F_{1}$ Hybrid Breeding}

Hybrid breeding exploits the increased vigor or heterosis of $F_{1}$ hybrid plants that is usually observed in crossbred species. In maize, a major yield improvement has been associated with the introduction of commercial hybrids. The average yield advantage of hybrids versus cultivars is approximately $15 \%$ (Tollenaar 1994). In rice, hybrids between indica $\times$ indica and indica $\times$ japonica lines have been investigated.

Three main strategies for hybrid rice breeding have been proposed: the three-line method using the cytoplasmic male sterility (CMS) system; a two-line method using the photoperiod-sensitive genic male sterile (PGMS) and thermo-sensitive genic male sterile (TGMS) system; and a one-line method using the apomixis system (Virmani and Kumar 2009). Existing rice hybrid varieties that are used commercially are mainly intervarietal hybrids that are based on the three-line method. This CMS $\mathrm{F}_{1}$ hybrid breeding system requires two lines carrying either a sterile $(S)$ or normal $(N)$ cytoplasm and a third line harboring nuclear fertility restorer $(R f)$ genes. To generate fertile $\mathrm{F}_{1}$ hybrids, a cytoplasmic male sterile line is mated with the $R f$ restorer line. The resulting hybrid seeds are fertile. The cytoplasmic male sterile line is also maintained by crossing it with a normal cytoplasm line (Khush 2001; http://www.fao.org/ docrep/006/Y4751E/y4751e0f.htm). Rice hybrids with a yield advantage of about $10-15 \%$ over the best known 
inbred varieties were introduced in China in mid-1970s and now account for about $50 \%$ of the rice grown (IRRI 2004). Rice hybrids that are adapted to tropical climates have been bred at the International Rice Research Institute (IRRI) and by several National Rice Improvement programs.

\section{Modification of Plant Architecture (Ideotype Breeding)}

Ideotype breeding is designed to modify the plant architecture and is a proven strategy to improve crop yield potentials. The yield potential of cereals such as rice, wheat, and sorghum has been successfully doubled through plant architecture modifications. Tall and traditional rice varieties have a yield potential of about $4 \mathrm{t}$ per hectare and produced about $12-13 \mathrm{t}$ of biomass per hectare. Of this, about $8 \mathrm{t}$ is straw and the $4 \mathrm{t}$ is grain which is a harvest index (HI) of 0.3 (Khush 2003). Improvements in the HI have been accomplished through the modification of the plant ideotype by reducing the plant height. This has been achieved through the incorporation of a recessive gene $s d l$ that encodes gibberellin 20 oxidase and confers short stature (Khush 1999; Sasaki et al. 2002). The first short statured rice variety, IR8, was developed at the IRRI and produced a biomass of $18 \mathrm{t}$ per hectare and a HI of 0.5. This equated to $9 \mathrm{t}$ of grain per hectare. In addition to its semidwarf stature, IR8 also had other desirable traits such as profuse tillering, dark green and erect leaves for good canopy architecture, and sturdy stems (Chandler 1969).

To further increase the yield potential of rice, a new plant type has now been conceptualized (IRRI 1989; Khush 2005). Semidwarf rice varieties produce a large number of unproductive tillers and excessive leaf areas which cause mutual shading and a reduction in canopy photosynthesis. IRRI scientists have proposed further modifications to the plant architecture with low tillering (9-10 tillers for transplanted conditions): no unproductive tillers, 200-250 grains per panicle, dark green, thick and erect leaves, and a vigorous and deep root system. This proposed ideotype has become regarded as the "New Plant Type" (NPT) of rice. The objective has been to develop improved germplasm with $15-20 \%$ higher yield than the existing best varieties. In recent years, new genes and QTL have been identified which control these proposed traits for NPT varieties.

\section{Control of Tillering}

In rice, secondary tillers are produced from the primary tiller via the formation of lateral leaves and axillary buds. The axillary buds grow into tillers (Xing and Zhang 2010). The first secondary tiller is visible when the main culm has a fourth leaf and a secondary tiller comes out of the leaf sheath on the primary tiller. It is known that grain yield is mainly contributed by the primary tillers and early secondary tillers, while the late secondary and tertiary tillers make very little contribution to yield but will compete for nutrients. Hence, reducing axillary bud formation is desirable and will increase yield potential. In maize, the Teosinte Branched1 (TB1) protein is known to repress the growth of axillary organs (Doebley et al. 1997). Transgenic rice plants overexpressing OsTB1, the rice ortholog of maize TB1, show reduced lateral branching, while a loss-of-function mutant of OsTB1 exhibits enhanced lateral branching (Takeda et al. 2003). This indicates that OsTB1 functions as a negative regulator of lateral branching in rice.

Several low or high tiller mutants of rice have been isolated and characterized. The monoculm mutant mocl exhibits a defect in the formation of tiller buds. MOC1 belongs to a plant-specific GRAS family that functions to initiate axillary buds and promote their outgrowth ( $\mathrm{Li}$ et al. 2003). In contrast, the rice mutants, $d 3, h t d 1, d 10, d 14$, and $d 27$, which have reduced plant heights, showed high tiller phenotypes. Interestingly, all causal genes for the high tiller mutants were found to encode proteins involved in the biosynthesis or signaling of strigolactones (SLs), a group of terpenoid lactones. These include D3, an F-box leucine rich-repeat (LRR) protein orthologous to Arabidopsis MEX2 (More Axillary Growth2) (Ishikawa et al. 2005); HTD1 (High-Tillering Dwarf1), the ortholog of Arabidopsis MEX3 (Zou et al. 2006); D10, a carotenoid cleavage dioxygenase 8 orthologous to MAX4 (Arite et al. 2007); D14, a member of the $\alpha / \beta$-fold hydrolase superfamily (Arite et al. 2009); and D27, an iron-containing protein (Lin et al. 2009). Furthermore, the application of SLs inhibits shoot branching in these mutants, indicating that these proteins represent a new hormone class that regulates the above-ground architecture in rice (Umehara et al. 2008).

The rice Fine Culm1 ( FCl) gene causes an increased tillering phenotype and was found to be allelic to OsTB1 (Minakuchi et al. 2010). The $f_{c} l$ mutant is insensitive to a high dose treatment of GR24, a synthetic SL analog, implying that proper $\mathrm{FCl}$ function is required for the SLs to inhibit bud growth. The overexpression of $F C 1$ partially rescues the $d 3$ mutant tiller growth and plant height phenotype. Hence, FC1/OsTB1 is suggested to partly function downstream of SL action.

Two research groups have cloned a QTL, OSSPL14 that controls tiller number. They have demonstrated that increased levels of OsSPL14 results in rice plants with fewer tillers but more productive panicles and consequently higher grain yields (Jiao et al. 2010; Miura et al. 2010). These recently discovered genetic resources should prove useful in the future for developing high-yielding NPT varieties of rice. 


\section{Control of Grain Formation}

Both the grain number per panicle and the grain weight are important traits for high yield varieties of rice. Grain numberla (Gnla), a QTL that increases grain productivity in rice, was found to encode a cytokinin oxidase/dehydrogenase, previously named OsCKX2. Cytokinin oxidase/ dehydrogenase is an enzyme that degrades the phytohormone cytokinin. The reduced expression of Gnla causes cytokinin accumulation in inflorescence meristems and increases the number of spikelets, thus enhancing grain yield (Ashikari et al. 2005). Based on the grain number per plant, a 34\% increase was found in the recessive Gnla allele-carrying line compared with its controls.

The rice lonely guy $(\log )$ mutant produces a small panicle with a reduced number of branches and flowers. The log gene was found to encode a novel cytokinin-activating enzyme that functions in the final step of active cytokinin synthesis by directly converting inactive cytokinin nucleotides to their free-base forms via its cytokinin-specific phosphoribohydrolase activity. Its transcript is specifically localized within shoot meristem tips, thus contributing to the fine-tuning of the concentration and spatial distribution of bioactive cytokinins that is essential for regulating meristem activity (Kurakawa et al. 2007). These results further confirm that cytokinin is critical for the formation of the panicles in rice.

Grain weight is determined by the size and filling of the grain, and the regulation of grain size is controlled by both its length and width (Xing and Zhang 2010). Regarding the grain size, the rice gene GS3, a major QTL with minor effects on grain width and thickness, encodes a putative transmembrane protein with a PEBP-like domain, a TNFR/ NGFR family cysteine-rich domain and a VWFC module. Sequence analysis has identified a nonsense mutation shared among all the large grain varieties in the GS3 gene. This mutation causes a 178-amino acid truncation at the $\mathrm{C}$ terminus, suggesting that the GS3 allele may function as a negative regulator of grain size (Fan et al. 2006).

$G W 2$, a QTL that controls rice grain width, encodes a RING-type protein with E3 ubiquitin ligase activity that functions in protein degradation via the ubiquitinproteasome pathway (Song et al. 2007). The gw2 mutant shows an increased cell number, resulting in a wider spikelet hull and accelerated grain-filling rate. This suggests that GW2 negatively regulates cell division by targeting its substrate(s) to the proteasomes for regulated proteolysis. $q S W 5$, a QTL involved in the determination of grain width in rice (also known as GW5) has been characterized in detail (Shomura et al. 2008). This study revealed that a deletion in $q S W 5$ results in a significant increase in sink size due to increased cell number in the glume of the spikelet (Shomura et al. 2008). qSW5 encodes a novel protein of 144 amino acids (qSW5/GW5) that is localized to the nucleus and that physically interacts with polyubiquitin in a yeast two-hybrid assay. These data suggest that both GW2 and qSW5 function in the ubiquitin-proteasome pathway to regulate cell division during seed development, possibly in the same pathway (Weng et al. 2008).

Grain-filling contributes greatly to grain weight. The rice GIF1 (Grain Incomplete Filling1) gene (also referred to as OsCIN2) encodes a cell-wall invertase enzyme that hydrolyzes sucrose to glucose and fructose and which is involved in carbon partitioning during early grain filling. Ectopic overexpression of the cultivated GIF1 allele with the $35 \mathrm{~S}$ or rice Waxy promoter results in smaller grains, whereas GIF1 expression driven by its native promoter increases grain production. Hence, a restricted expression pattern of the GIF1 gene in cultivated rice compared with wild rice allele may be essential for grain filling (Wang et al. 2008).

\section{Erect Leaves}

It has been proposed that erect leaves that enhance light capture for photosynthesis and nitrogen storage for grain filling could increase grain yields in rice cultivars (Sinclair and Sheehy 1999). A rice brassinosteroid (BR)-deficient mutant, Osdwarf4-1, has an erect leaf phenotype that is associated with enhanced grain yields under dense planting conditions. OsDwarf4 is a homolog of Arabidopsis Dwarf4 encoding a cytochrome P450, CYP90B1 (Sakamoto et al. 2005). Molecular and biochemical studies have further revealed that two different cytochrome P450s, OsDwarf4 and D11, function redundantly in the rate-limiting step of BR biosynthesis. Hence, the OsDwarf4 mutation alone causes only limited defects in BR biosynthesis and plant morphology.

The weakest allele of the rice $d 61$ mutants, d61-7, confers agronomically important traits including an erect leaf phenotype due to a loss of function of a BR receptor OsBRI1. The biomass of $d 61-7$ has been shown to be $35 \%$ higher than wild type at a high planting density. This indicates that $d 61-7$ more effectively assimilates biomass during reproductive organ development at a high planting density. Further, transgenic rice with only partial suppression of endogenous OsBRI1 produces about a 30\% higher yield than wild type at a high planting density (Morinaka et al. 2006). In addition, antisense expression of OsBAK 1 , a coreceptor of OsBRI1, produces a desirable weak BRinsensitive mutant phenotype with erect leaves and normal reproduction ( $\mathrm{Li}$ et al. 2009). These results demonstrate the feasibility of generating erect leaf rice plants by modifying BR synthesis or signaling.

\section{Strong Root Systems}

Roots are an important part of the plant architecture and are not only involved in foraging for water and nutrients but 
also provide anchorage for the plant in soil. With a deep and thick root system, plants get better access to nutrients and water and show reduced lodging. The root-specific expression of the OSNAC10, a rice NAC (No Apical Meristem), ATAF12, and $C U C 2$ (Cup-Shaped Cotyledon) gene, using the rootspecific promoter $R C c 3$, resulted in thicker roots $(1.25$-fold increase in root diameter) due to the enlarged stele, cortex, and epidermis. These transgenic rice plants also had an increased grain yield of $5-14 \%$ and $25-42 \%$ over the controls under normal and drought conditions, respectively (Jeong et al. 2010). These results clearly demonstrate that thick roots can enhance the yield potential of rice.

Upland rice varieties when grown with no irrigation usually have deeper roots than their lowland counterparts (Araki and Iijima 2005). Genetic analysis of a population derived from a cross between lowland and upland varieties with contrasting root development characteristics has identified a large number of QTLs. Further intensive data mining has identified 861 root development QTLassociated microsatellite markers. This work provides a good platform for the isolation of candidate genes for strong root traits in the future (Suryapriya et al. 2009).

\section{Enhancement of Photosynthesis}

Current research on the enhancement of photosynthetic efficiency in rice includes the delaying of leaf senescence and the engineering of the $\mathrm{C}_{4}$ photosynthetic machinery.

\section{Delaying of Leaf Senescence}

In several crop species, the incorporation of a "stay green" trait has been a major achievement for breeders (Evans 1993). Genotypes with the stay green trait (slower senescence) show prolonged canopy photosynthesis and thus give higher yields. While the nonfunctional stay green trait retains leaf greenness without sustaining photosynthetic activity, the functional stay green trait delays leaf senescence, thus maintaining photosynthetic competence. The functional stay green trait is thus beneficial and desirable and can enhance grain yield in rice. A functional stay green rice mutant, SNUSG1, has been isolated and shows a high grain yield. Molecular marker analyses have identified two QTLs that most influence the functional stay green ability (Yoo et al. 2007). Cloning of these QTLs should assist in our future understanding of the molecular basis for achieving sustained photosynthetic activity for longer periods.

Engineering of $\mathrm{C}_{4}$ Rice

The differences in the solar energy use efficiency between $\mathrm{C}_{3}$ and $\mathrm{C}_{4}$ plants is nearly $50 \%$. Engineering the $\mathrm{C}_{4}$ photosynthetic machinery into $\mathrm{C}_{3}$ rice strains is considered to be a key strategy for dramatically raising rice yields (Hibberd et al. 2008; Zhu et al. 2010a). All domesticated $\mathrm{C}_{4}$ crops have the "Kranz" anatomy, and to achieve the goal of converting rice into a $\mathrm{C}_{4}$ variety, it may be necessary to alter the leaf morphology so that it is similar to that of $\mathrm{C}_{4}$ plants. While $\mathrm{C}_{4}$ maize has a narrower vein spacing, $\mathrm{C}_{3}$ rice has a wider vein spacing. The wild rice relatives, Oryza barthii and Oryza australiensis have a relatively narrower vein spacing compared with cultivated rice. Rice mutants with a decreased interveinal space may be utilized to introduce some of morphological features of the $\mathrm{C}_{4}$ pathway. Alternatively, it would be valuable to examine the leaf morphology in $\mathrm{C}_{3}$ rice strains that show an altered photosynthetic metabolism. For example, the induction of high levels of NADP-malic enzyme (NADP-ME), a component of the $\mathrm{C}_{4}$ pathway, into rice has led to a reduced stacking of the thylakoids in chloroplasts (Takeuch et al. 2000). This indicates that an altered metabolite flux may cause an altered leaf morphology.

Molecular engineering strategies have also been employed to introduce the known biochemical components of $\mathrm{C}_{4}$ into rice. For example, overexpression of the maize phosphoenolpyruvate carboxylase (PEPC) gene in rice has produced a two- to threefold higher activity of this enzyme than that in maize, and the enzyme itself accounted for up to $12 \%$ of the total leaf-soluble protein. The PEPC transgenic plants also exhibited reduced $\mathrm{O}_{2}$ inhibition of photosynthesis. These results suggest a possible strategy for introducing the key biochemical component of the $\mathrm{C}_{4}$ pathway of photosynthesis into $\mathrm{C}_{3}$ plants ( $\mathrm{Ku}$ et al. 1999; Matsuoka et al. 2001).

Systems biology research may also play a pivotal role in identifying key regulatory factors that control the essential $\mathrm{C}_{4}$ biochemical and anatomical features required to achieve high photosynthetic efficiency in rice (Zhu et al. 2010b). As a contribution to this effort, we have identified the rice orthologs for five major enzymes involved in the $\mathrm{C}_{4}$ photosynthetic pathway and generated a hypothetical $\mathrm{C}_{4}$ pathway in rice by combining it with the Calvin cycle (Fig. 1). All genes were identified using the Gramene pathway tool, ricecyc (http://www.gramene.org/pathway/ ricecyc.html) (Liang et al. 2008; Jung et al. 2008b, c). The expression comparison data from dark-grown versus light-grown rice seedlings were incorporated into our hypothetical pathway. The expression levels of genes encoding four components of the $\mathrm{C}_{4}$ pathway were increased under dark conditions. These were PEPC (Os02g14770), pyruvate orthophosphate dikinase (PPDK; Os03g31750), NADP-ME (Os1g09320), and carbonic anhydrase (CA; Os09g28910). Interestingly, transcripts for NADP-malate dehydrogenase (MDH; Os08g44810), PEPC (Os08g27840) and CA (Os01g45274), accumulated under 


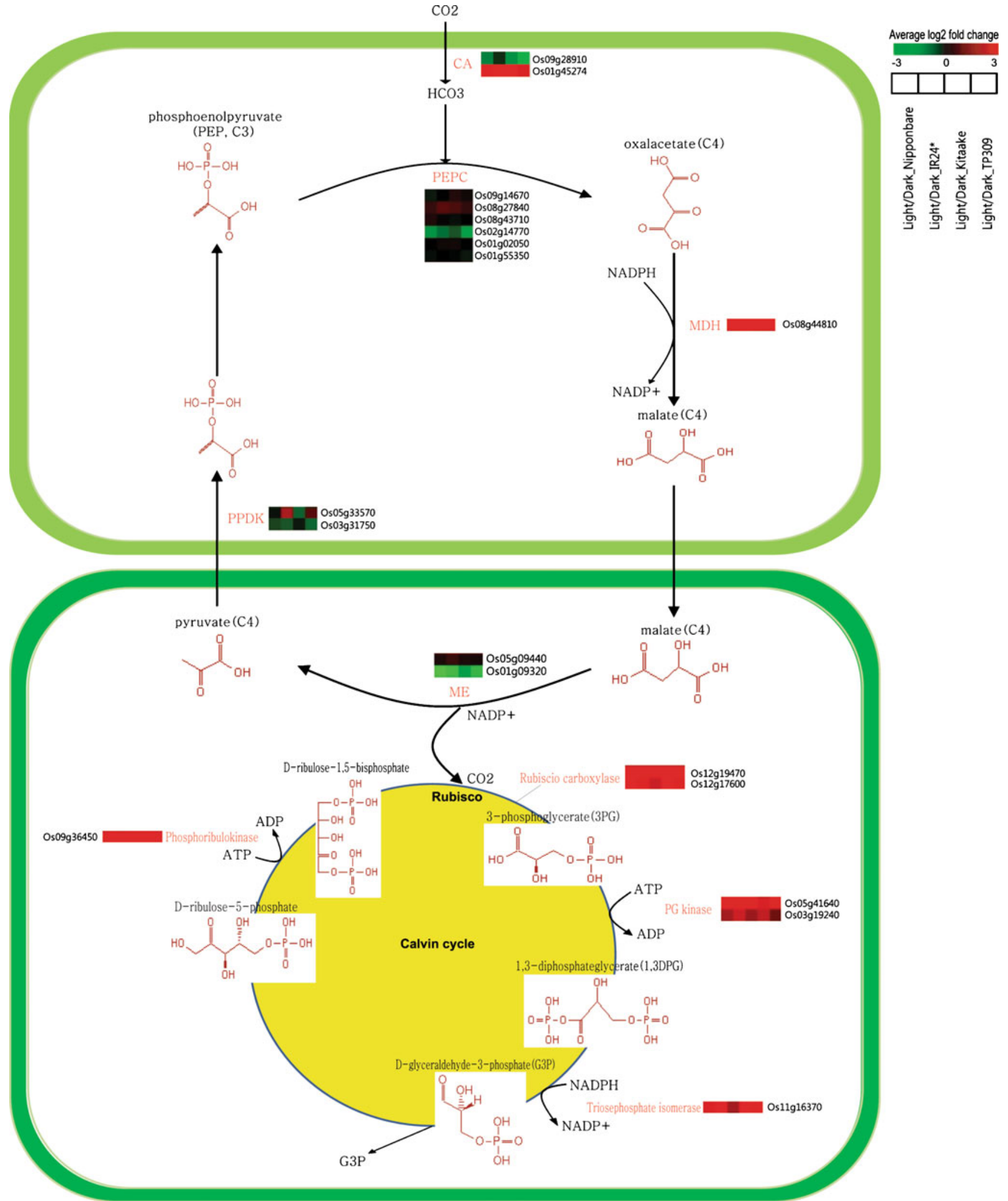


Fig. 1 A hypothetical $\mathrm{C}_{4}$ photosynthetic pathway in rice. The five components of the $\mathrm{C}_{4}$ photosynthesis pathway in rice were identified from Plantcyc curated by Gramene. Four major components of the Calvin cycle were also selected. Rice microarray data for light- versus dark-grown seedlings of four rice varieties, Nipponbare, IR24, Kitaake and TP309, were integrated. IR24 is an indica cultivar and all others are japonica. Red in the heatmap indicates upregulation in light and green indicates downregulation. With regards to the $\mathrm{C}_{4}$ photosynthesis pathway, carbonic anhydrase (CA) catalyzes the rapid conversion of $\mathrm{CO}_{2}$ and $\mathrm{H}_{2} \mathrm{O}$ to $\mathrm{HCO}_{3}{ }^{-}$and $\mathrm{H}^{+}$; phosphoenolpyruvate carboxylase (PEPC) catalyzes the addition of $\mathrm{CO}_{2}$ to phosphoenolpyruvate (PEP) to form the four-carbon compound oxaloacetate; NADP-malate dehydrogenase $(\mathrm{MDH})$ catalyzes the conversion of oxaloacetate to malate; NADP-malic enzyme (NADP-ME) catalyzes the oxidative decarboxylation of L-malate, producing pyruvate, $\mathrm{CO}_{2}$, and NADPH. In the Calvin cycle, Rubisco carboxylase catalyzes the first major step of carbon fixation; 3-phosphoglycerate kinase (PG kinase) catalyzes the transfer of a phosphate group from 1,3-biphosphoglycerate to ADP, forming ATP and 3-phosphoglycerate (PG); triosephosphate isomerase catalyzes the reversible interconversion of the triose phosphate isomers dihydroxyacetone phosphate and D-glyceraldehyde 3-phosphate; and phosphoribulokinase catalyzes the conversion of ATP and D-ribulose 5-phosphate to ADP and D-ribulose light conditions. Transcripts for Calvin cycle components such as Rubisco carboxylase, 3-phosphoglyceric acid (PG) kinase, triose phosphate isomerase, and phosphoribulokinase, also accumulated largely under conditions of light. This analysis indicates that while all components of the $\mathrm{C}_{4}$ pathway exist in rice, the expression pattern of some of the rice $\mathrm{C}_{4}$ enzyme genes has become evolutionarily differentiated from that of the common $\mathrm{C}_{4}$ genes. Hence, a strategy that involves the fine regulation of these components may shed new light on the possibility of engineering an efficient $\mathrm{C}_{4}$ pathway in rice.

\section{Prospects}

The resources to allow systematic approaches to improve agronomically desirable traits are now available for rice. These include over 1,700 genome-wide transcriptome data, a protein-protein interaction network dataset, a web-based
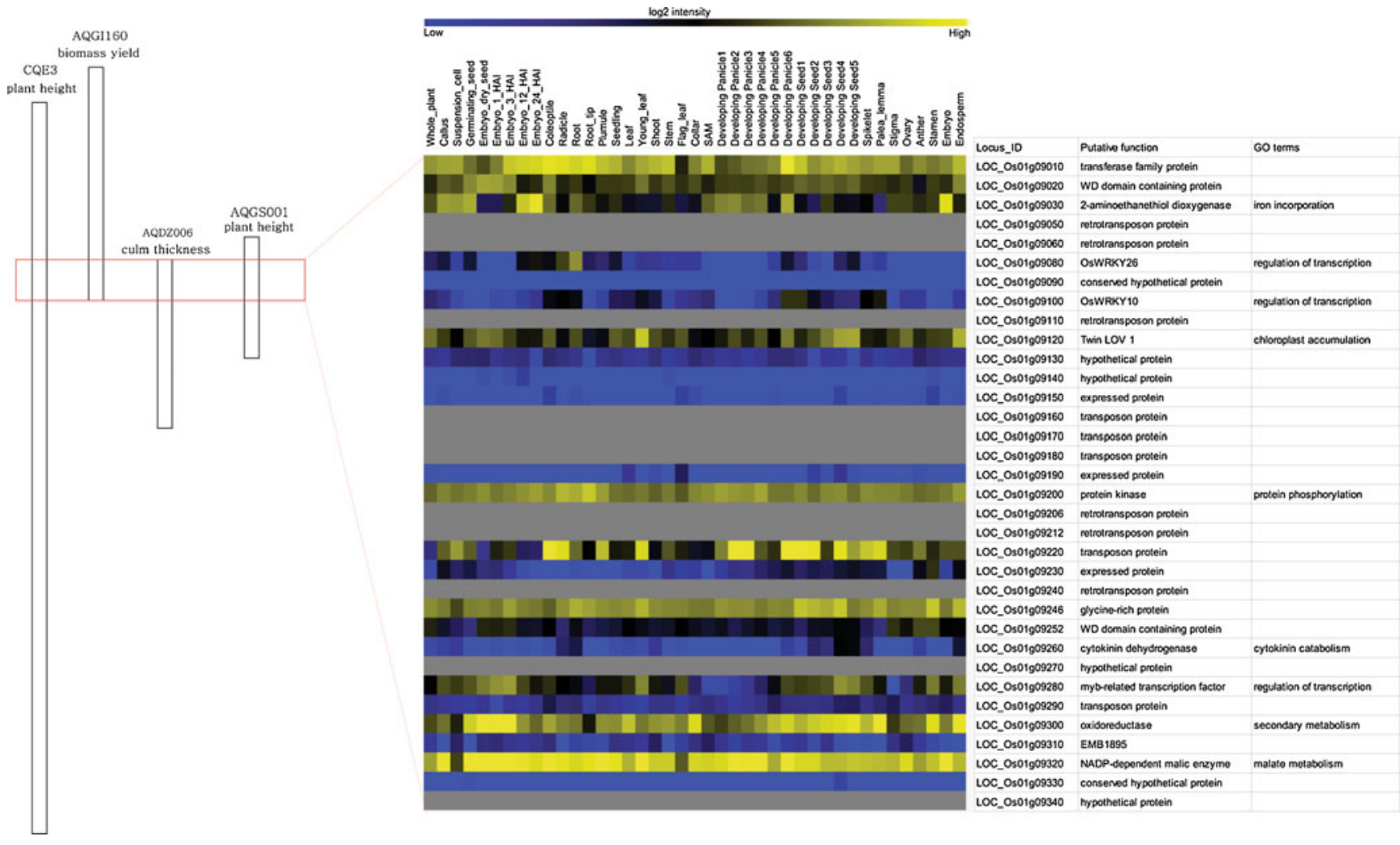

Fig. 2 In silico analysis to pinpoint the target regions associated with the QTLs related to biomass yield potential. The first step was to select the target QTLs associated with an important trait (i.e., biomass yield) by using the QTL database developed by Gramene. The second step involved the mapping of the QTLs to the gene loci. The third step was to identify overlapping regions among QTLs with similar features. The last step integrates multiomics data to the loci for the overlapping region. The GO terms were combined with anatomical gene expression data that had been reorganized by sorting about 830 Affymetrix gene chip results available from NCBI gene expression omnibus (GEO, http://www.ncbi.nlm.nih.gov/geo/) Plant Expression Database (PlexDB, http://www.plexdb.org/) and Arrayexpress (http:// www.ebi.ac.uk/microarray-as/ae/). SAM shoot apical meristem, Developing panicle 1 panicles of less than $3 \mathrm{~cm}$ in length, Developing panicle 2 3-5 cm, Developing panicle 3 5-10 cm, Developing panicle $410-15 \mathrm{~cm}$, Developing panicle $515-22 \mathrm{~cm}$, Developing panicle 6 more than $22 \mathrm{~cm}$, Developing seed 1 0-2 days post pollination (dap) seeds, Developing seed 2 3-4 dap seeds, Developing seed 3 5-10 dap seeds, Developing seed 4 11-20 dap seeds, Developing seed 5, 21-29 dap seeds 
tool to integrate transcriptome or proteomic data into genome-wide metabolic pathways, and a large gene indexed mutant population (Liang et al. 2008; Jung et al. 2008a). Intensive phenotype datasets using these gene indexed mutant resources will soon also be accessible. Using these multiomic resources, it has now become possible to select the key components responsible for desirable traits to improve rice yields. To date, information on over 8,600 rice QTLs has also been collected and curated by the database "Gramene" (Ni et al. 2009). Hence, in silico QTL analysis, combined with genome-wide omics data, will help pinpoint the target regions associated with the rice QTLs of interest by exploring the loci that are enriched by similar traits. A future strategy for the in silico analysis of a QTL associated with biomass yield potential is shown in Fig. 2. The four QTLs previously identified as CQE3 (plant height), AQC1160 (biomass yield), AQDZ006 (Culm thickness), and AQGS001 (plant height), respectively, share a target region containing 34 genes on rice Chromosome 1. Interestingly, this region includes a gene (Os01g09320) encoding NADP-ME which is a key component of $\mathrm{C}_{4}$ photosynthesis. In gene expression profiles of 42 anatomical samples collected from a public microarray database, the NADP-ME gene shows high expression in most cases. This suggests that the gene is a strong candidate for a biomass yield QTL, although this has not been confirmed as yet. It will be of great value in the future to develop a database that integrates rice QTLs into an all multiomics dataset. Finally, this well-integrated resource should help identify novel components that can be utilized to generate higher yielding rice varieties.

Acknowledgements This work was supported by grants from the Crop Functional Genomics Center (CFGC) of the 21st Century Frontier Research Program (CG2111-2) and the World Class University program (R33-2008-000-10168-0) of the Korean Ministry of Education, Science and Technology.

Open Access This article is distributed under the terms of the Creative Commons Attribution Noncommercial License which permits any noncommercial use, distribution, and reproduction in any medium, provided the original author(s) and source are credited.

\section{References}

Araki H, Iijima M (2005) Stable isotope analysis of water extraction from subsoil in upland rice (Oryza sativa L.) as affected by drought and soil compaction. Plant Soil 270:147-157

Arite T, Iwata H, Ohshima K, Maekawa M, Nakajima M, Kojima M, Sakakibara H, Kyozuka J (2007) Dwarf10, an RMS1/MAX4/ DAD1 ortholog, controls lateral bud outgrowth in rice. Plant J 51:1019-1029

Arite T, Umehara M, Ishikawa S, Hanada A, Maekawa M, Yamaguchi S, Kyozuka J (2009) d14, a strigolactone-insensitive mutant of rice, shows an accelerated outgrowth of tillers. Plant Cell Physiol 50:1416-1424
Ashikari M, Sakakibara H, Lin SY, Yamamoto T, Takashi T, Nishimura A, Angeles ER, Qian Q, Kitano H, Matsuoka M (2005) Cytokinin oxidase regulates rice grain production. Science 309:741-745

Brar DS, Khush GS (1997) Wide hybridization for rice improvements: alien gene transfer and molecular characterization of introgression. In: Jones MP, Dingkhun M, Johnson DE, Fagade SO (eds) Interspecific hybridization: progress and prospect. WARDA, Bouaké, pp 21-29

Chandler RF Jr (1969) Plant morphology and stand geometry in relation to nitrogen. In: Eastin JD, Haskin FA, Sullivan CY, Van Baul CHM (eds) Physiological aspects of crop yield. ASA, Madison, pp 265-285

Chen J, Ding J, Ouyang Y, Du H, Yang J, Cheng K, Zhao J, Qiu S, Zhang X, Yao J, Liu K, Wang L, Xu C, Li X, Xue Y, Xia M, Ji Q, Lu J, Xu M, Zhang Q (2008) A triallelic system of S5 is a major regulator of the reproductive barrier and compatibility of indica-japonica hybrids in rice. Proc Natl Acad Sci USA 105:11436-11441

Doebley J, Stec A, Hubbard L (1997) The evolution of apical dominance in maize. Nature 386:485-488

Evans LT (1993) Raising the ceiling to yield: key role of synergism between agronomy and plant breeding. In: Muralidharan K, Siddiq EA (eds) New frontiers in rice research. Directorate of Rice Research, Hyderabad, pp 103-107

Fan C, Xing Y, Mao H, Lu T, Han B, Xu C, Li X, Zhang Q (2006) GS3, a major QTL for grain length and weight and minor QTL for grain width and thickness in rice, encodes a putative transmembrane protein. Theor Appl Genet 112:11641171

Hibberd JM, Sheehy JE, Langdale JA (2008) Using $\mathrm{C}_{4}$ photosynthesis to increase the yield of rice-rationale and feasibility. Curr Opin Plant Biol 11:228-231

IRRI (1989) IRRI towards 2000 and beyond. International Rice Research Institute, Manila, p 66

IRRI (2004) Rice experts converge on a rare opportunity. Rice today 3:27-30

Ishikawa S, Maekawa M, Arite T, Onishi K, Takamure I, Kyozuka J (2005) Suppression of tiller bud activity in tillering dwarf mutants of rice. Plant Cell Physiol 46:79-86

Jeong JS, Kim YS, Baek KH, Jung H, Ha SH, Do Choi Y, Kim M, Reuzeau C, Kim JK (2010) Root-specific expression of OsNAC10 improves drought tolerance and grain yield in rice under field drought conditions. Plant Physiol 153:185-197

Jiao Y, Wang Y, Xue D, Wang J, Yan M, Liu G, Dong G, Zeng D, Lu Z, Zhu X, Qian Q, Li J (2010) Regulation of OsSPL14 by OsmiR156 defines ideal plant architecture in rice. Nat Genet 42:541-554

Jung K, An G, Ronald PC (2008a) Towards a better bowl of rice: assigning function to tens of thousands of rice genes. Nat Rev Genet 9:91-101

Jung K, Lee J, Dardick C, Seo YS, Cao P, Canlas P, Phetsom J, Xu X, Ouyang S, An K, Cho YJ, Lee GC, Lee Y, An G, Ronald PC (2008b) Identification and functional analysis of light-responsive unique genes and gene family members in rice. PLoS Genet 4: e1000164

Jung K, Dardick C, Bartley LE, Cao P, Phetsom J, Canlas P, Seo YS, Shultz M, Ouyang S, Yuan Q, Frank BC, Ly E, Zheng L, Jia Y, Hsia AP, An K, Chou HH, Rocke D, Lee GC, Schnable PS, An G, Buell CR, Ronald PC (2008c) Refinement of light-responsive transcript lists using rice oligonucleotide arrays: evaluation of gene-redundancy. PLoS ONE 3:e3337

Khush GS (1999) Green revolution: preparing for the 21st century. Genome 42:646-655

Khush GS (2001) Green revolution: the way forward. Nat Rev Genet 2:815-822 
Khush GS (2003) Productivity improvements in rice. Nutr Rev 61: S114-S116

Khush GS (2005) What it will take to feed 5.0 billion rice consumers in 2030. Plant Mol Biol 59:1-6

$\mathrm{Ku}$ MS, Agarie S, Nomura M, Fukayama H, Tsuchida H, Ono K, Horose S, Toki S, Miyao M, Matsuoka M (1999) High-level expression of maize phosphoenolpyruvate carboxylase in transgenic rice plants. Nat Biotechnol 17:76-80

Kurakawa T, Ueda N, Maekawa M, Kobayashi K, Kojima M, Nagato Y, Sakakibara H, Kyozuka J (2007) Direct control of shoot meristem activity by a cytokinin-activating enzyme. Nature 445:652-655

Li X, Qian Q, Fu Z, Wang Y, Xiong G, Zeng D, Wang X, Liu X, Teng S, Hiroshi F, Yuan M, Luo D, Han B, Li J (2003) Control of tillering in rice. Nature 422:618-621

Li D, Wang L, Wang M, Xu YY, Luo W, Liu YJ, Xu ZH, Li J, Chong K (2009) Engineering OsBAK1 gene as a molecular tool to improve rice architecture for high yield. Plant Biotechnol J 7:791-806

Liang C, Jaiswal P, Hebbard C, Avraham S, Buckler ES, Casstevens T, Hurwitz B, McCouch S, Ni J, Pujar A, Ravenscroft D, Ren L, Spooner W, Tecle I, Thomason J, Tung CW, Wei X, Yap I, YouensClark K, Ware D, Stein L (2008) Gramene: a growing plant comparative genomics resource. Nucleic Acids Res 36:D947-D953

Lin H, Wang R, Qian Q, Yan M, Meng X, Fu Z, Yan C, Jiang B, Su Z, Li J, Wang Y (2009) Dwarf27, an iron-containing protein required for the biosynthesis of strigolactones, regulates rice tiller bud outgrowth. Plant Cell 21:1512-1525

Long Y, Zhao L, Niu B, Su J, Wu H, Chen Y, Zhang Q, Guo J, Zhuang C, Mei M, Xia J, Wang L, Wu H, Liu YG (2008) Hybrid male sterility in rice controlled by interaction between divergent alleles of two adjacent genes. Proc Natl Acad Sci USA 105:18871-18876

Matsuoka M, Fukayama H, Ku MS, Miyao M (2001) High level expression of $\mathrm{C}_{4}$ photosynthetic genes in transgenic rice. In: Khush GS, Brar DS, Hardy B (eds) Rice genetics IV. International Rice Research Institute, Los Baños, pp 439-447

Minakuchi K, Kameoka H, Yasuno N, Umehara M, Luo L, Kobayashi $\mathrm{K}$, Hanada A, Ueno K, Asami T, Yamaguchi S, Kyozuka J (2010) Fine Culm 1 (FC1) works downstream of strigolactones to inhibit the outgrowth of axillary buds in rice. Plant Cell Physiol $51: 1127-1135$

Miura K, Ikeda M, Matsubara A, Song XJ, Ito M, Asano K, Matsuoka M, Kitano H, Ashikari M (2010) OsSPL14 promotes panicle branching and higher grain productivity in rice. Nat Genet 42:545-549

Mohanty S, Wailes E, Chavez E (2010) The global rice supply and demand outlook: the need for greater productivity growth to keep rice affordable. In: Pandey S, Byerlee D, Daw D, Dobermann A, Mohanty S, Rozelle S, Hardy B (eds) Rice in global economy, strategic and policy research for food security. IRRI, Los Baños, pp 175-187

Morinaka Y, Sakamoto T, Inukai Y, Agetsuma M, Kitano H, Ashikari M, Matsuoka M (2006) Morphological alteration caused by brassinosteroid insensitivity increases the biomass and grain production of rice. Plant Physiol 141:924-931

Ni J, Pujar A, Youens-Clark K, Yap I, Jaiswal P, Tecle I, Tung CW, Ren L, Spooner W, Wei X, Avraham S, Ware D, Stein L, McCouch S (2009) Gramene QTL database: development, content and applications. Database (Oxford) 2009:bap005

Ouyang Y, Liu YG, Zhang Q (2010) Hybrid sterility in plant: stories from rice. Curr Opin Plant Biol 13:186-192

Peng S, Laza RC, Visperas RM, Sanico AL, Cassman KG, Khush GS (2000) Grain yield of rice cultivars and lines developed in the Philippines since 1966. Crop Sci 40:307-314

Peng S, Tang Q, Zou Y (2009) Current status and challenges of rice production in China. Plant Prod Sci 12:3-8
Sakamoto T, Morinaka Y, Ohnishi T, Sunohara H, Fujioka S, Ueguchi-Tanaka M, Mizutani M, Sakata K, Takatsuto S, Yoshida S, Tanaka H, Kitano H, Matsuoka M (2005) Erect leaves caused by brassinosteroid deficiency increase biomass production and grain yield in rice. Nat Biotech 24:105-109

Sasaki A, Ashikari M, Ueguchi-Tanaka M, Itoh H, Nishimura A, Swapan D, Ishiyama K, Saito T, Kobayashi M, Khush GS, Kitano H, Matsuoka M (2002) Green revolution: a mutant gibberellin-synthesis gene in rice. Nature 416:701-702

Shomura A, Izawa T, Ebana K, Ebitani T, Kanegae H, Konishi S, Yano M (2008) Deletion in a gene associated with grain size increased yields during rice domestication. Nat Genet 40:1023-1028

Sinclair TR, Sheehy JE (1999) Erect leaves and photosynthesis in rice. Science 283:1455

Song XJ, Huang W, Shi M, Zhu MZ, Lin HX (2007) A QTL for rice grain width and weight encodes a previously unknown RINGtype E3 ubiquitin ligase. Nat Genet 39:623-630

Suryapriya P, Snehalatha A, Kayalvili U, Krishna AR, Singh S, Ulaganathan K (2009) Genome-wide analyses of rice root development QTLs and development of an online resource, Rootbrowse. Bioinformation 3:279-28

Takeda T, Suwa Y, Suzuki M, Kitano H, Ueguchi-Tanaka M, Ashikari M, Matsuoka M, Ueguchi C (2003) The OsTB1 gene negatively regulates lateral branching in rice. Plant J 33:513-520

Takeuch K, Akagi H, Kamasawa N, Osumi M, Honda H (2000) Aberrant chloroplasts in transgenic rice plants expressing a high level of maize NADP-dependent malic enzyme. Planta 211:265-274

Tollenaar M (1994) Yield potential of maize: impact of stress tolerance. In: Cassman KG (ed) Breaking the yield barrier. Proceedings of a workshop on rice yield potential in favorable environments. International Rice Research Institute, Manila, pp 103-109

Umehara M, Hanada A, Yoshida S, Akiyama K, Arite T, TakedaKamiya N, Magome H, Kamiya Y, Shirasu K, Yoneyama K, Kyozuka J, Yamaguchi S (2008) Inhibition of shoot branching by new terpenoid plant hormones. Nature 455:195-200

Virmani SS, Kumar I (2009) Hybrid rice technology. In: Datta SK (ed) Rice improvement in the genomics era. CRC, Fl Boca Raton, pp $105-137$

Wang E, Wang J, Zhu X, Hao W, Wang L, Li Q, Zhang L, He W, Lu B, Lin H, Ma H, Zhang G, He Z (2008) Control of rice grainfilling and yield by a gene with a potential signature of domestication. Nat Genet 40:1370-1374

Weng J, Gu S, Wan X, Gao H, Guo T, Su N, Lei C, Zhang X, Cheng Z, Guo X, Wang J, Jiang L, Zhai H, Wan J (2008) Isolation and initial characterization of $G W 5$, a major QTL associated with rice grain width and weight. Cell Res 18:1199-1209

Xiao J, Grandillo S, Ahn SN, McCouch SR, Tanksley SD, Li Z, Yuan L (1996) Genes from wild rice improve yield. Nature 384:1223-1224

Xing Y, Zhang Q (2010) Genetic and molecular bases of rice yield. Ann Rev Plant Biol 61:421-442

Yamagata Y, Yamamoto E, Aya K, Win KT, Doi K, Sobrizal, Ito T, Kanamori H, Wu J, Matsumoto T, Matsuoka M, Ashikari M, Yoshimura A (2010) Mitochondrial gene in the nuclear genome induces reproductive barrier in rice. Proc Natl Acad Sci USA 107:1494-1499

Yoo SC, Cho SH, Zhang H, Paik HC, Lee CH, Li J, Yoo JH, Lee BW, Koh HJ, Seo HS, Paek NC (2007) Quantitative trait loci associated with functional stay-green $S N U-S G 1$ in rice. Mol Cells 24:83-94

Zhu XG, Long SP, Ort DR (2010a) Improving photosynthetic efficiency for greater yield. Ann Rev Plant Biol 61:235-261

Zhu XG, Shan L, Wang Y, Quick WP (2010b) $\mathrm{C}_{4}$ rice - an ideal arena for systems biology research. J Integr Plant Biol 52:762-770

Zou J, Zhang S, Zhang W, Li G, Chen Z, Zhai W, Zhao X, Pan X, Xie Q, Zhu L (2006) The rice High-Tillering Dwarf1 encoding an ortholog of Arabidopsis MAX3 is required for negative regulation of the outgrowth of axillary buds. Plant J 48:687-698 